\section{Terminology of bioanalytical} methods (IUPAC Recommendations 2018)

Ján Labuda, et al.

Pure and Applied Chemistry, 2018

published online ahead of print 29 May 2018

Bioanalytical chemistry is a branch of science that represents large and dynamic areas of research and practical analytical activities, from human health screening (medical, clinical, food, and pharmaceutical analysis) to forensic analysis and from basic biochemistry studies to special apparatus development. Bioanalytical chemistry and biochemical analysis often require special methods for sampling and sample preparation and for handling biomolecules, including isolation, purification, separation, and fragmentation. Special attention is paid to apparatus and to techniques with immobilised bioreceptors (biosensors, bioarrays). The methods of analysis and identification of biomacromolecules are radically different from those used to analyse relatively small organic molecules. Most "classical" analytical methods are not suitable for the analysis of biomacromolecules or are suitable only to a limited extent.

Recommendations are given concerning the terminology of methods of bioanalytical chemistry. With respect to dynamic development particularly in the analysis and investigation of biomacromolecules, terms related to bioanalytical samples, enzymatic methods, immunoanalytical methods, methods used in genomics and nucleic acid analysis, proteomics, metabolomics, glycomics, lipidomics, and biomolecules interaction studies are introduced.

These recommendations will become part of a chapter in the revised Orange Book (Compendium of Terminology in Analytical Chemistry, $4^{\text {th }}$ edition).

\section{https://doi.org/10.1515/pac-2016-1120}

\section{Reorienting chemistry education through systems thinking}

Peter G. Mahaffy, Alain Krief, Henning Hopf, Goverdhan Mehta, and Stephen A. Matlin Nature Reviews Chemistry 2, Article number: 0126 (2018)

A framework for analysis of systems thinking in chemistry education, consisting of three nodes or subsystems, has been published, which sets the context for the IUPAC project titled Learning Objectives

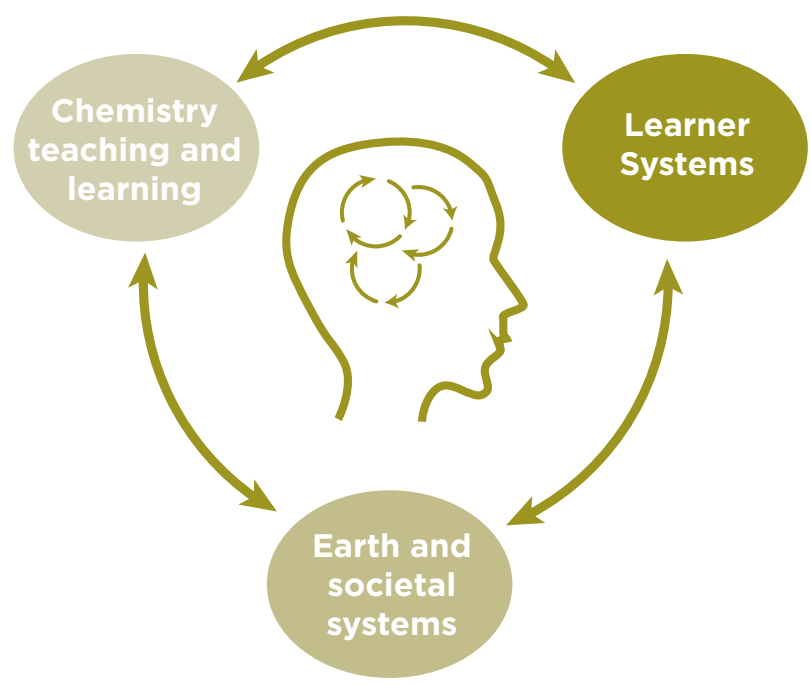

and Strategies for Infusing Systems Thinking into (Post)-Secondary General Chemistry Education (https://iupac.org/project/2017-010-1-050 ). The project goals are to guide educators and students to see more clearly the relevance of chemistry education for addressing challenges such as sustainability, alternative energy, planetary boundaries, and the UN Sustainable Development Goals. The next project milestone will be activities (a plenary talk, symposium, workshop, and a project meeting of the task force) at the $25^{\text {th }}$ IUPAC International Conference on Chemistry Education (ICCE) in Sydney, 10-14 July 2018.

https://doi.org/10.1038/s41570-018-0126

\section{Clarification of the term "normal material" used for standard atomic weights (IUPAC Technical Report)}

Tyler B. Coplen, Norman E. Holden, Michael E. Wieser, and John Karl Böhlke

Pure and Applied Chemistry, 2018

published online ahead of print 25 May 2018

The standard atomic weights of the elements apply to normal materials. Since 1984, the Commission on Isotopic Abundances and Atomic Weights (Commission) has defined a normal material as:

"The material is a reasonably possible source for this element or its compounds in commerce, for industry or science; the material is not itself studied for some extraordinary anomaly and its isotopic composition has not been modified significantly in a geologically brief period." 
The term "a geologically brief period" in this definition is confusing, and confusion can be reduced by revising this definition to the following, which was accepted by the Commission on Isotopic Abundances and Atomic Weights at its meeting in Groningen, Netherlands in September 2017:

"Normal materials include all substances, except (1) those subjected to substantial deliberate, undisclosed, or inadvertent artificial isotopic modification, (2) extraterrestrial materials, and (3) isotopically anomalous specimens, such as natural nuclear reactor products from Oklo (Gabon) or other unique occurrences."

\section{https://doi.org/10.1515/pac-2017-0301}

\section{Corrigendum}

The following two Pure and Applied Chemistry references were announced in the last April Cl (page 43) but the references were erroneously interchanged. Instead, Nordberg et al was published in issue 4 of PAC, while Nordin et a/ was at that time only available Ahead Of Print and it has since appeared in issue 5. The full references and DOI are restated below:
Risk assessment of effects of cadmium on human health (IUPAC Technical Report)

Gunnar F. Nordberg, Alfred Bernard, Gary L. Diamond, John H. Duffus, Paul Illing, Monica Nordberg, Ingvar A. Bergdahl, Taiyi Jin and Staffan Skerfving

Pure and Applied Chemistry, 2018

Volume 90, Issue 4, pp. 755-808

https://doi.org/10.1515/pac-2016-0910

Vocabulary on nominal property, examination, and related concepts for clinical laboratory sciences (IFCC-IUPAC Recommendations 2017)

Gunnar Nordin, René Dybkaer, Urban Forsum, Xavier Fuentes-Arderiu and Françoise Pontet Pure and Applied Chemistry, 2018

Volume 90, Issue 5, pp. 913-935

https://doi.org/10.1515/pac-2011-0613

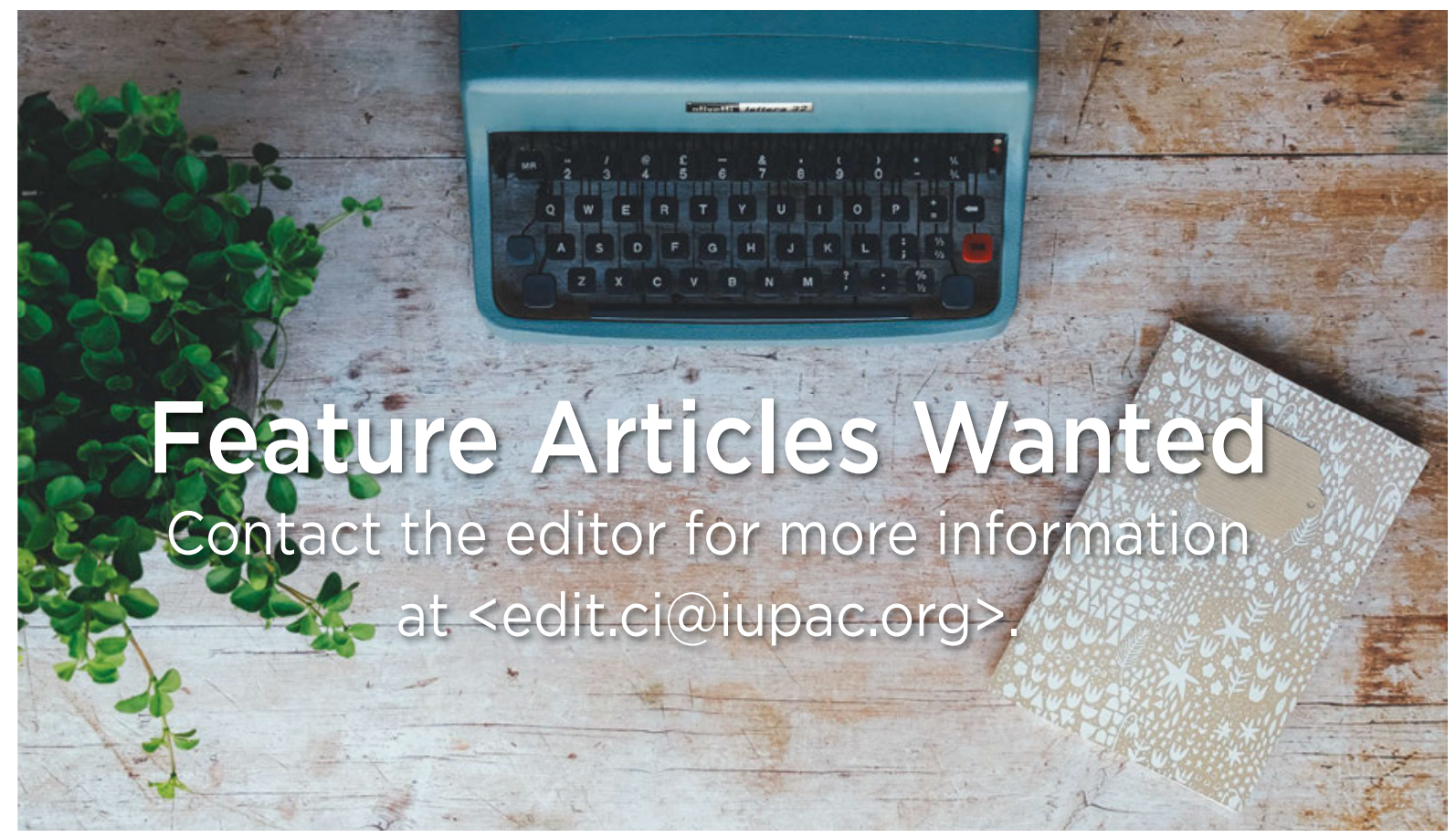

